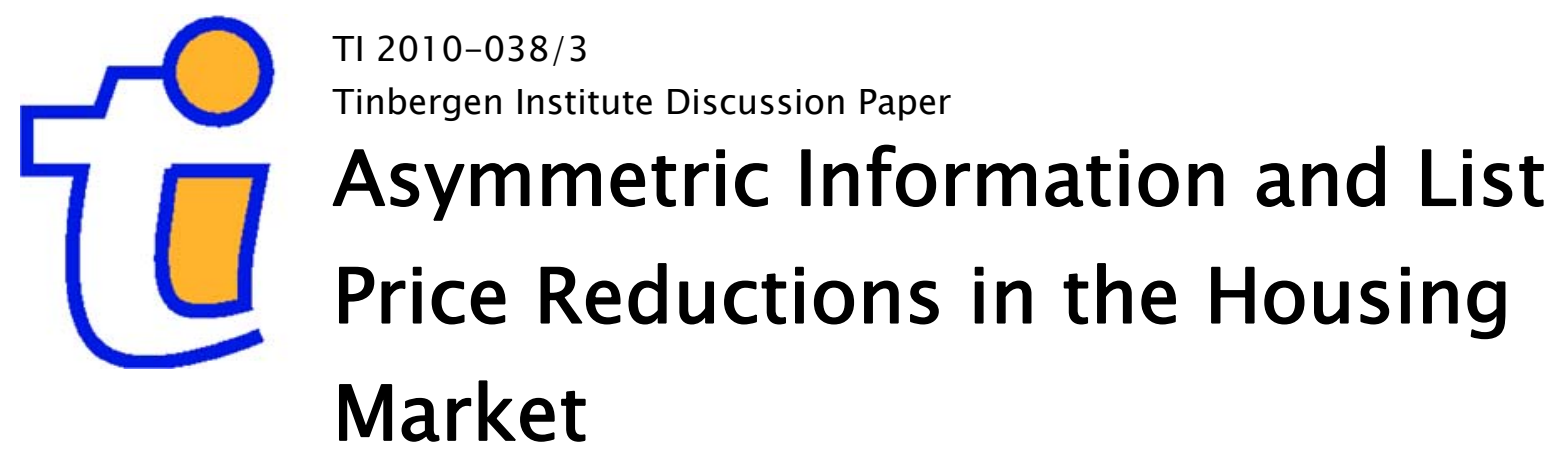

Erik R. de Wit ${ }^{1,3}$

Bas van der Klaauw²,3

' Finance Group, University of Amsterdam;

2 Dept. of Economics, VU University Amsterdam, and CEPR;

3 Tinbergen Institute. 


\section{Tinbergen Institute}

The Tinbergen Institute is the institute for economic research of the Erasmus Universiteit Rotterdam, Universiteit van Amsterdam, and Vrije Universiteit Amsterdam.

Tinbergen Institute Amsterdam

Roetersstraat 31

1018 WB Amsterdam

The Netherlands

Tel.: +31(0)205513500

Fax: $+31(0) 205513555$

Tinbergen Institute Rotterdam

Burg. Oudlaan 50

3062 PA Rotterdam

The Netherlands

Tel.: + $31(0) 104088900$

Fax: $+31(0) 104089031$

Most TI discussion papers can be downloaded at http://www.tinbergen.nl. 


\title{
Asymmetric Information and List Price Reductions in the Housing Market
}

\author{
Erik R. de Wit* Bas van der Klaauw ${ }^{\dagger}$
}

April 2010

\begin{abstract}
In housing markets with asymmetric information list prices may signal unobserved properties of the house or the seller. Asymmetric information is the starting point of many models for the housing market. In this paper, we estimate the causal effect of list-price reductions to test for the presence of asymmetric information. We use very rich and extensive administrative data from the Netherlands. Our empirical results show that list-price reductions significantly increase the probability of selling a house, but also the rate of withdrawal from the market increases.
\end{abstract}

\footnotetext{
*Finance Group - University of Amsterdam, Tinbergen Institute. e.r.dewit@uva.nl

${ }^{\dagger}$ Department of Economics - VU University Amsterdam, Tinbergen Institute, and CEPR.bklaauw@feweb.vu.nl

We are grateful to the Amsterdam School of Real Estate and the NVM (Dutch Association of Real Estate Brokers and Real Estate Experts) for providing the data.
} 


\section{Introduction}

Heterogeneity in the housing market is often considered to be quite substantial. Houses, for example, differ in size, location and quality. Many of such house characteristics are revealed to potential buyers when a house is put up for sale on the market. In fact, real estate brokers often add an extensive list of house characteristics including pictures to their advertisements of houses for sale. However, there may remain characteristics, which are known to the seller, but unobserved by potential buyers. This may not only be characteristics of the house, but may also relate to the seller. Sellers may, for example, differ in risk preference, financial constraints and patience. An important question is to which extent such information asymmetries are important in the housing market.

In this paper, we focus on how changes in the list price affect the time a house remains on the market. List prices are not binding in the housing market. In the Netherlands list prices have no formal role, and by law sellers have to provide all relevant information about the house. The lack of any legal commitment implies that if the market is characterized by symmetric information between buyers and sellers, the list price will not have any effect on outcomes. However, in case of asymmetric information, the list price may signal some unobserved properties of the house or the seller (e.g. Albrecht, Gautier and Vroman, 2010). More patient sellers may, for example, set a higher list price than desperate sellers.

Estimating the causal effect of the list price on outcomes in the housing market is complicated. There may be characteristics which are observed by both buyers and sellers, but which are unobserved by the econometrician. For example, the thinness of the market for a particular house affects both the list price and the probability of selling the house (e.g. Lazear, 1986). Therefore, we focus on the effect of changes in list prices while a house is on the market, rather than the initial level of the list price. However, Lazear (1986) shows that also changes in the list price are not exogenous, market thinness may also affect list price changes. We use a timing-of-events duration model to

estimate the causal effect of a list price change on the time a house is on the market. The empirical model builds on Abbring and Van den Berg (2003) 
who show that identification of the causal effect of a list price change depends on the market not anticipating the exact moment at which the list prices is reduced. No anticipation only implies that buyers do not know the exact moment at which the list price is lowered. The actual list price reduction thus causes a shock to the market. Buyers may, however, know that certain houses are at risk of lowering the list price or that list prices are likely to be lowered in certain time periods. No anticipation thus does not imply that list price reductions are exogenous, or that the rate at which list prices are reduced is the same over time. Houses may have different rates at which house prices are reduced, and it may be that during particular periods a house price reduction is more likely than in other periods. We thus explicitly allow for selection on unobservables. Also if some houses never lower the list price (i.e., the duration distribution until lowering the list price is defective), the model is identified.

We not only focus on the time until selling the house, but also allow for the option to withdraw a house from the market. Withdrawing a house from the market is not exogenous (e.g. Taylor, 1999). We explicitly incorporate this in our model by having competing risks. This implies that we estimate the causal effect of a list price change on both the probability of selling the house and the probability of withdrawing the house from the market.

We use a unique administrative data set from the Dutch NVM (Association of Real Estate Brokers and Real Estate Experts) on houses put for sale on the Dutch housing market during the period 2005-2007. The data contain daily information on the time the house was on the market. Also the reason for leaving the market is recorded, so we also observe houses withdrawn from the market by the seller. Such information is not trivial. Caplin and Leahy (1996) discuss the consequences of self selection in markets with frictions such as real estate markets, when only sales are observed. Withdrawal data contain important information about the selling process (e.g. Taylor, 1999). The data contain not only the initial list price, but are also informative on the moments and magnitudes of all list-price changes. Furthermore, we observe a very extensive set of characteristics of each house.

Our paper contributes to two earlier studies considering list price changes. Both Knight (2002) and Merlo and Ortalo-Magné (2004) provide descriptive 
evidence on list price reductions. Knight (2002) suggests that high initial list prices are costly to the seller. Those houses with large reductions in initial list prices take longer to sell and ultimately sell at lower prices. Merlo and Ortalo-Magné (2004) establish a number of stylized facts of bidding behavior and list price changes.

The remainder of the paper is organized as follows. Section 2 describes the institutional setting of the Dutch market for owner occupied houses. Section 3 describes our empirical model that is inspired by the theoretical literature. Section 4 describes the unique administrative data set. Section 5 presents the estimation results and some sensitivity analyses. Section 6 concludes.

\section{Owner Occupied Housing Market in the Netherlands}

In this section, we describe some institutions of the Dutch housing market. We mainly focus on owner occupied sector, and highlight aspects relevant for our purposes. According to Statistics Netherlands in 2006, 56\% of the seven million households in the Netherlands were living in an owner occupied house. The average price of owner occupied houses was $€ 235,842$, which is 4.57 times the average household income.

During the 1990s the Dutch housing market experienced a large real price increase. Apart from a growth in real income, this price increase is often explained from population growth, stringent spatial planning policies reducing the construction of new houses, reduced interest rates on mortgages, and changes in the Dutch mortgage finance market. ${ }^{1}$ Usually banks restrict mortgages to 4.5 times the household income, but in exceptional cases they give higher mortgages. There is no restricting on the loan-to-value ratio. Ball (2009) indicates that in 2007 the loan-to-value ratio of first-time buyers was $114 \%$.

There are substantial transaction costs associated to purchasing a house.

\footnotetext{
${ }^{1}$ Since 1990 mortgages can be based on total household income rather than the income of the highest earner. Furthermore, during the 1990s new mortgage products were introduced which exploited more the existing tax benefits. Interest payments on mortgages are currently for 30 years $100 \%$ deductable.
} 
For existing houses there is a transaction tax of $6 \%$, which is absent for new houses. Broker costs are between $1 \%$ and $3 \%$ of the selling price, and mortgage often have a $1 \%$ to $1.5 \%$ initiation fee. Furthermore, there are notary fees and possible intermediary fees. Total transaction costs are approximately $10 \%$ of the selling price, and are often financed by including them in the mortgage principle.

Usually when selling a house, the seller approaches a real estate broker. Most real estate brokers are connected to the NVM. Actually, about $70 \%$ of all houses offered for sale are offered through a member of the NVM. The broker advises the seller on an appropriate list price, but the seller determines the list price. The real estate broker adds the house on a publicly available website with a list price, a detailed description on the characteristics and some pictures. This website also contains information about socioeconomic characteristics of the neighborhood. The seller can also choose to advertise in media such as local newspapers. An interested potential buyer contacts the broker for information on the house or to visit the house. A visit to the house is usually hosted by the broker, and the seller will not be present.

In the Netherlands, list prices do not have a formal role as list prices are not binding. So even if a buyer is willing to pay the list price, a seller can refuse or try to negotiate a higher price. There are some rules for negotiating with potential buyers. Potential buyers communicate their bids to the broker. The broker will then contact the seller and this starts the negotiation process. It is not allowed to negotiate with multiple buyers at the same time or to reveal bids to other buyers. Furthermore, the seller should negotiate with potential buyers in the order in which they made their first bid. Finally, if after selling the house it turns out that there are defects to the house, the buyer can hold the seller liable for the costs of repairing (even in case the buyer inspected the house during the sale). The seller thus has by law the obligation to reveal all information about the house. 


\section{The Model}

\subsection{Theoretical Framework}

An early model for the housing market was developed by Olsen (1969). Because it is a model of perfect competition and symmetric information, list prices play no role. Lazear (1986) provides a two-period model in which list prices are actually important. Sellers face uncertainty about buyers' valuations, and learn in the first period. Therefore, second-period list prices are lower than in the first period. The price setting is related to market thinness. In a thin market, sellers receive less strong signals about the buyers' valuation. Therefore, they start with a lower initial price and prices decrease less rapidly. However, the model imposes that the object is sold to the first buyer who is willing to pay the list price. This assumption makes the model less suitable for the housing market. However, it indicates that list prices and list-price changes are often not exogenous.

Also Taylor (1999) develops a two-period model, but he allows for twosided asymmetric information. Also in this model list prices are binding. The model is specified such that sellers cannot use the list price to signal the quality of their house. Houses that remain on the market for a long time become stigmatized, and can eventually be removed from the market as sale becomes unlikely. This is the consequence of buyer herding and information cascades, which can arise if second-period buyers do not observe list-price histories and inspections are not public. The latter might imply that highquality sellers will reveal as much information as possible to the market, and low-quality sellers mimic their behavior. Indeed, empirical evidence confirms that the probability of sales decreases with time on the market (e.g. De Wit, 2009; Huang and Palmquist, 2001; Pryce and Gibb, 2006; and Zuehlke, 1987). However, withdrawal from the market is not exogenous to selling the house, and empirical analyses should take this into account.

Both Horowitz (1992) and Haurin, Haurin, Nadauld and Sanders (2006) presents a model in which buyers never bid above the list price. In both models bids arrive and sellers have to decide to reject or accept a bid immediately. Haurin, Haurin, Nadauld and Sanders (2006) assume that the rate at which 
bids arrive reduces in the level of the list price. Horowitz (1992) imposes that the distribution of bids depends on the list price, which could be interpreted as the seller revealing information about the (unobserved) reservation price to the market. Both models explain why sellers choose list prices, and expressions for the optimal list price are derived. However, the bidding behavior of buyers is very mechanic, and not driven by any underlying optimization.

Albrecht, Gautier and Vroman (2010) explicitly model the behavior of buyers in the housing market. They allow list prices to be used as signals. In their model sellers differ in the reservation value for their house, but this is private information. Such heterogeneity might arise because some sellers already hold a new house (e.g. Wheaton, 1990). Search of buyers is directed, so based on the list price they determine which house to visit. After visiting a house, buyers receives a match-specific value. In equilibrium, list prices reveal the seller's type. Sellers with a higher reservation value set a higher list price. Even though list price are not binding, the list price has both an effect of the selling price and the probability of sale. In particular, sellers who post a higher list price are less likely to sell their house, but receive a higher selling price. This only holds if sellers are heterogenous, and the source of heterogeneity is unobserved by buyers. If sellers would be homogenous, there would not be any role for list prices.

The key conclusion is that if list prices are not binding, in the absence of asymmetric information list prices do not play any role (Albrecht, Gautier and Vroman, 2010). This implies that the level of the list price does not affect the probability of sale. It is important to distinguish between information known to the market and to the econometrician. For example, market thinness within particular segments may be known to both buyers and sellers, but is unknown to the econometrician (Lazear, 1986). Furthermore, the econometrician should explicitly take account of withdrawing as this might not be exogenous in a housing market of asymmetric information (Taylor, 1999). 


\section{$3.2 \quad$ Empirical Model}

The main conclusion from the theoretical literature is that if list prices are not binding, they only play a relevant role in the case of asymmetric information. In particular, Albrecht, Gautier and Vroman (2010) show that list prices are used for signaling the (unobserved) seller type, and list prices are thus related to the probability of sale. The key empirical problem is that list prices are endogenous. There may be relevant market characteristics that are observed by both the buyer and the seller, which are unobserved by the econometrician. Therefore, we focus on list-price changes rather than the level of the list price. We use the timing-of-events model to estimate the causal effect of a list-price change on the probability of selling the house (e.g. Abbring and Van den Berg, 2003). Furthermore, we jointly model withdrawals from the market, as Taylor (1999) shows that withdrawing a house may not be exogenous in a market of asymmetric information.

Before we provide the details of our econometric model, we first give a brief outline of the data. Our data contains houses which became for sale between January 2005 and December 2007. For each house we observed the exact date of entering the market, the date of leaving the market, and the reason for leaving the market (sale or withdrawal). Furthermore, we observe the initial list price, and the date and magnitudes of all possible list-price changes while the house was on the market. It should be noted that we only focus on the first list-price change. About $20 \%$ of the houses entering the market change list price, but only in $0.76 \%$ of the case the list price is changed more than once.

Consider a house which is put on the market at (calender) date $\tau_{0}$. Our model is a continuous-time duration model in which $t$ denotes the time a house is already on the market and $t_{p}$ the moment of changing the list price. Let $\theta_{s}$ denote the rate at which houses are sold, and $\theta_{w}$ the rate at which houses are withdrawn from the market. These transition rates can depend on the duration the house is already on the market $t$, calendar time $\tau_{0}+$ $t$, observed characteristics $x$, some characteristics $v$ which are observed by the market but unobserved to the econometrician, and a variable indicating whether a list price was lowered $I\left(t_{p}<t\right)$ (with $I(\cdot)$ the indicator function). 
Lowering a list price has a permanent effect on the rate at which houses are sold and the rate at which houses are withdrawn. We relax this assumption in Subsection 5.2 when we perform a number of sensitivity analyses.

We denote the unobserved term $v$ in the rate of selling the house by $v_{s}$, and in the rate of withdrawing by $v_{w}$. These terms are allowed to be correlated to each other, but are assumed to be independent of $x$ and $\tau_{0}$. Since the variables in $x$ are mainly used as control variables, and we will not causally interpret their covariate effect, this is not a strong assumption. Conditional on $\tau_{0}, x, v_{s}$ and $t_{p}$, the rate at which a house is sold after $t$ periods on the market follows a familiar mixed proportional hazard specification

$$
\theta_{s}\left(t \mid x, v_{s}, t_{p}\right)=\lambda_{s}(t) \psi_{s}\left(\tau_{0}+t\right) \exp \left(x^{\prime} \beta_{s}+\delta_{s} \cdot I\left(t_{p}<t\right)+v_{s}\right)
$$

And a similar specification is used for the rate at which houses are withdrawn from the market

$$
\theta_{w}\left(t \mid x, v_{w}, t_{p}\right)=\lambda_{w}(t) \psi_{w}\left(\tau_{0}+t\right) \exp \left(x^{\prime} \beta_{w}+\delta_{w} \cdot I\left(t_{p}<t\right)+v_{w}\right)
$$

In these specification $\psi_{s}\left(\tau_{0}+t\right)$ and $\psi_{w}\left(\tau_{0}+t\right)$ are genuine calendar-time effects modeled by dummies for each quarter. The functions $\lambda_{s}(t)$ and $\lambda_{w}(t)$ represent duration dependence, which might, for example, be the consequence of stigmatization. Although, it should be noted that in a housing market with symmetric information, time on the market does not provide a signal to the market and the duration dependence term should thus be constant. The parameters $\delta_{s}$ and $\delta_{w}$ are the key parameters of interest as these denote the causal effect of a list-price reduction on the rate at which houses are sold and withdrawn. In case of symmetric information, list prices should be irrelevant. Our test for symmetric information thus consist of testing if $\delta_{s}$ and $\delta_{w}$ are equal to zero.

The timing of list-price reductions $t_{p}$ are most likely not exogenously determined. Therefore, we jointly model the timing of list-price reductions also using a mixed proportional hazard specification

$$
\theta_{p}\left(t \mid x, v_{p}\right)=\lambda_{p}(t) \psi_{p}\left(\tau_{0}+t\right) \exp \left(x^{\prime} \beta_{p}+v_{p}\right)
$$


The rate $\theta_{p}$ thus denotes the rate of lowering a list price if no list-price reduction has yet occurred while the house was on the market. The rate depends on the same set of observed characteristics $x$ as the rate at which house are sold and withdrawn.

Now consider the joint distribution of $t_{s}, t_{w}$ and $t_{p}$. Conditional on $\tau_{0}$, $x, v_{s}, v_{w}$ and $v_{p}$, the only possible relation between $\left(t_{s}, t_{w}\right)$ and $t_{p}$ is by way of the direct effect of a list-price change on the selling rate and the rate of withdrawal. In case of independence between $\left(v_{s}, v_{w}\right)$ and $v_{p}$, we would have a standard competing-risks model for $\left(t_{s}, t_{w}\right) \mid x, \tau_{0}, t_{p}$ with $I\left(t_{p}<t\right)$ a time-varying regressor which is orthogonal to the unobserved heterogeneity $\left(v_{s}, v_{w}\right)$. However, if $\left(v_{s}, v_{w}\right)$ and $v_{p}$ are not independent, inference on $\left(t_{s}, t_{w}\right) \mid x, \tau_{0}, t_{p}$ has to be based on $\left(t_{s}, t_{w}, t_{p}\right) \mid x, \tau_{0}$. Let $G\left(v_{s}, v_{w}, v_{p}\right)$ be the joint distribution function of the unobserved characteristics $\left(v_{s}, v_{w}, v_{p}\right)$.

It is straightforward to derive the likelihood contributions from the specifications of the different hazard rates. The use of a flow sample of houses entering the market implies that we do not have any initial conditions problems. The right-censoring in the data is exogenous, and is, therefore, solved in a straightforward manner. In particular, let $c_{s}$ equal one if a house is observed to be sold, $c_{w}$ is one if the destination state was withdrawal, and $c_{p}$ indicates if the list price was reduced. If $i=1, \ldots, n$ denote the observations, then the loglikelihood function equals

$$
\begin{array}{r}
\log \ell=\sum_{i=1}^{n} \log \left\{\int_{v_{s}} \int_{v_{w}} \int_{v_{p}} \theta_{s}\left(t_{i} \mid x_{i}, \tau_{0, i}, v_{s}, t_{p, i}\right)^{c_{s, i}} \theta_{w}\left(t_{i} \mid x_{i}, \tau_{0, i}, v_{w}, t_{p, i}\right)^{c_{w, i}}\right. \\
\exp \left(-\int_{0}^{t_{i}} \theta_{s}\left(z \mid x_{i}, \tau_{0, i}, v_{s}, t_{p, i}\right)+\theta_{w}\left(z \mid x_{i}, \tau_{0, i}, v_{w}, t_{p, i}\right) d z\right) \\
\left.\theta_{p}\left(t_{p, i} \mid x_{i}, \tau_{0, i}, v_{p}\right)^{c_{p, i}} \exp \left(-\int_{0}^{t_{p, i}} \theta_{p}\left(z \mid x_{i}, \tau_{0, i}, v_{p}\right) d z\right) d G\left(v_{s}, v_{l}, v_{p}\right)\right\}
\end{array}
$$

If the house was still on the market at the end of the observation period $\left(c_{s}=c_{w}=0\right)$, then $t$ equals the duration until right-censoring. Furthermore, if during the time on the market no list-price reduction has been observed $\left(c_{p}=0\right)$, then $t_{p}$ is set equal to the time $t$ the house was on the market (which is the moment of censoring the duration until a list-price reduction).

Abbring and Van den Berg (2003) provide an extensive discussion on 
the identification of such models. The key identifying assumptions for the causal effects $\delta_{s}$ and $\delta_{w}$ of list-price reductions is that such reductions are not anticipated. Formally, no anticipation of the exact moment of the list-price reduction implies that for $t_{d} \neq t_{d}^{\prime}$ and $t<t_{d}, t_{d}^{\prime}$, it should be that

$$
\theta_{s}\left(t \mid x, v_{s}, t_{d}\right)=\theta_{s}\left(t \mid x, v_{s}, t_{d}^{\prime}\right) \quad \text { and } \quad \theta_{w}\left(t \mid x, v_{w}, t_{d}\right)=\theta_{w}\left(t \mid x, v_{w}, t_{d}^{\prime}\right)
$$

This thus implies that conditional on both observed and unobserved characteristics, the current selling rate and the current rate of withdrawal do not depend on the exact moment of a future list-price reduction. No anticipation thus does not imply that list-price reductions are exogenous, or that the rate at which list prices are reduced is continuous over time. Houses (based on both observed and unobserved characteristics) may have different rates at which list prices are reduced, and it may be that during particular periods a list-price reduction is more likely than in other periods. We thus explicitly allow for selection on unobservables. Also if some houses never lower the list price (i.e., the duration distribution until lowering the list price is defective), the model is identified.

It may be clear that in this setting the assumption of no anticipation is satisfied. Obviously buyers are not informed a priori about a list-price reduction. List-price reductions thus come as a shock. Furthermore, sellers do not know when potential buyers arrive and bid for their house. If the assumption of no anticipation is satisfied, no exclusions restrictions or very strong functional-form restrictions are necessary to identify the causal effects of list-price reductions. To provide some intuition for the identification, first note that the data can be broken into two parts: $(i)$ a competing-risks part for the duration until a house leaves the market (after being sold or taken off the market) or a lowering of the list price, whichever comes first, and (ii) the residual duration from the moment of lowering the list price until the house leaves the market. From Heckman and and Honoré (1989) it follows that under general conditions the whole model except for $\delta_{s}$ and $\delta_{w}$ is identified from the data corresponding to the competing-risks part. Subsequently, $\delta_{s}$ and $\delta_{w}$ are identified from the data corresponding to part (ii) of the model, i.e. the residual duration on the market after a list-price reduction. Abbring 
and Van den Berg (2003) show that the causal effects of list-price reductions $\delta_{s}$ and $\delta_{w}$ are allowed to depend on $t, \tau_{0}, x$ and $v$. We exploit this is in the sensitivity analyses discussed in Subsection 5.2.

\subsection{Parameterization}

For the duration dependence functions and the trivariate unobserved heterogeneity distribution we take the most flexible specifications used to date (e.g. Heckman and Singer, 1984). We take $\lambda_{s}(t), \lambda_{w}(t)$ and $\lambda_{p}(t)$ to have a piecewise constant specification,

$$
\lambda_{i}(t)=\exp \left(\sum_{j=1,2, \ldots} \lambda_{i j} I_{j}(t)\right) \quad i=s, w, p
$$

where $j$ is a subscript for duration intervals, and $I_{j}(t)$ are time-varying dummy variables that are one in consecutive time intervals. Note that with an increasing number of intervals any duration dependence pattern can be approximated arbitrarily closely. We normalize the pattern of duration dependence by fixing $\lambda_{i 1}=0$.

We take the joint distribution of the unobserved heterogeneity terms $v_{s}$, $v_{w}$ and $v_{p}$ to be trivariate discrete with unrestricted mass-point locations for each term. In particular, we allow for $K$ terms

$$
\operatorname{Pr}\left(v_{s}=v_{s}^{k}, v_{w}=v_{w}^{k}, v_{p}=v_{p}^{k}\right)=p_{k} \quad \text { for } \quad k=1, \ldots, K
$$

with $p_{1}+\ldots+p_{K}=1$. For $K \geq 2$ this specification allows for dependence between the different unobservable heterogeneity terms. The degree of flexibility increases with $K$. We do not restrict the locations of the mass points, but instead we normalize the model by not including an intercept in the vector of observed characteristics $x$.

\section{The Data}

Our data contain all houses and apartments offered for sale through all real estate brokers associated to the Dutch NVM between January 2005 and 
December 2007. This covers about $70 \%$ of all houses and apartments offered for sale in the Netherlands. For each house (and apartment) we observe the exact date when it was put on the market, and the initial list price. We also observe the exact date at which the house was sold or was taken off the market. If it was still on the market on January 1, 2008, the time on the market is exogenously right censored. Furthermore, we observe the exact dates and the sizes of all revisions of the list price.

For each house, we observe a rich set of characteristics. There is information on the type of house (12 types), the construction period ( 5 periods), parking facility (4 types), garden location (9 types), and region (76 regions). ${ }^{2}$ The data also include several size characteristics such as the floorsize, lotsize (in square meters), and the number of rooms in the house. Furthermore, we observe whether the dwelling is well isolated, type of heating system (3 types), location next to a quiet road, possible groundlease, presence of an elevator in the apartment building, and two variables measuring inside and outside quality on a discrete scale from 1 to 9 . These quality measures are determined by the real estate broker selling the house.

Table 1 presents some details of the data. In total our data contain 498,369 houses put on the market. For 369,611 houses we observe a sale, 51,092 houses were taken off the market, and 77,666 houses were still on the market at the end of the observation period. On average, the initial list price is $€ 274,367$ (although the average initial list price for houses which did sell was substantially lower at $€ 259,410$ ), and the average selling price is $€ 246,614$. About $89 \%$ of the houses are sold below the list price. It should, however, be noted that the average list-price premium for houses which experienced a list-price reduction was $1.82 \%$ versus $-1.14 \%$ for houses which did not experience a list-price reduction. ${ }^{3}$

\footnotetext{
${ }^{2}$ Within a NVM region $80 \%$ of the families changing house stay within the region.

${ }^{3}$ The list-price premium is the difference between the log of the initial list price of the house and the predicted log value of the initial list price of the dwelling. The predicted log value of the list price is based on standard loglinear regressions separately performed for each year (e.g. Rosen, 1974). The R-squared for these regressions are $79.8 \%, 80.1 \%$ and $80.2 \%$ for 2005, 2006 and 2007, respectively. This approach is identical to that in Merlo and Ortalo-Magné (2004). The variable gives us a measure of overpricing or underpricing of the house based on what would be a "normal" list price for the house based on observed characteristics.
} 
Table 1: Some characteristics of the data set.

\begin{tabular}{lr}
\hline \hline Number of observations & 498,369 \\
Number of sales & 369,611 \\
Number of withdrawals & 51,092 \\
Number of right censored & 77,666 \\
& \\
Number of list-price reductions & 101,896 \\
Average list-price reduction & $5.5 \%$ \\
& \\
Average selling price & $€ 246,614$ \\
Average list price & $€ 274,367$ \\
& \\
Average list price premium: & $1.82 \%$ \\
for houses which list price was reduced & $-1.14 \%$ \\
for houses which list price was not reduced & \\
\hline \hline
\end{tabular}

Note.-List-price premium is the difference between the log of the initial list price of the house and the predicted log value of the initial list price of the house. The predicted log value of the list price is based on a log-linear hedonic regression.

Figure 1 shows the Kaplan-Meier estimates for the survival function for selling the house and withdrawing from the market (without sale). When estimating the survivor function for selling the house, withdrawing is considered to be exogenous, and vice versa. This also implies that the probability that a house is still on the market after some duration is the product of the survivor to selling the house and the survivor for withdrawal. If no houses would have been withdrawn before, about $50 \%$ of the houses is sold after 108 days. Withdrawal is a much slower process, it takes 665 days before the probability of withdrawn reached 0.5 .

In total, for 101,896 dwellings we observe a list-price reduction during the period the dwelling was on the market. Only $0.76 \%$ of the dwellings for which a list price has been reduced, experience a subsequent reduction in the list price. Therefore, in the empirical analyses we only focus on the first listprice reduction. Figure 2 shows the survivor function for repricing the house. Within the first 100 days less than $13 \%$ of the houses is repriced. After that period the probability of repricing increases. However, it still takes 299 days before the probability of repricing reaches 0.5 . If a list price is reduced, the 


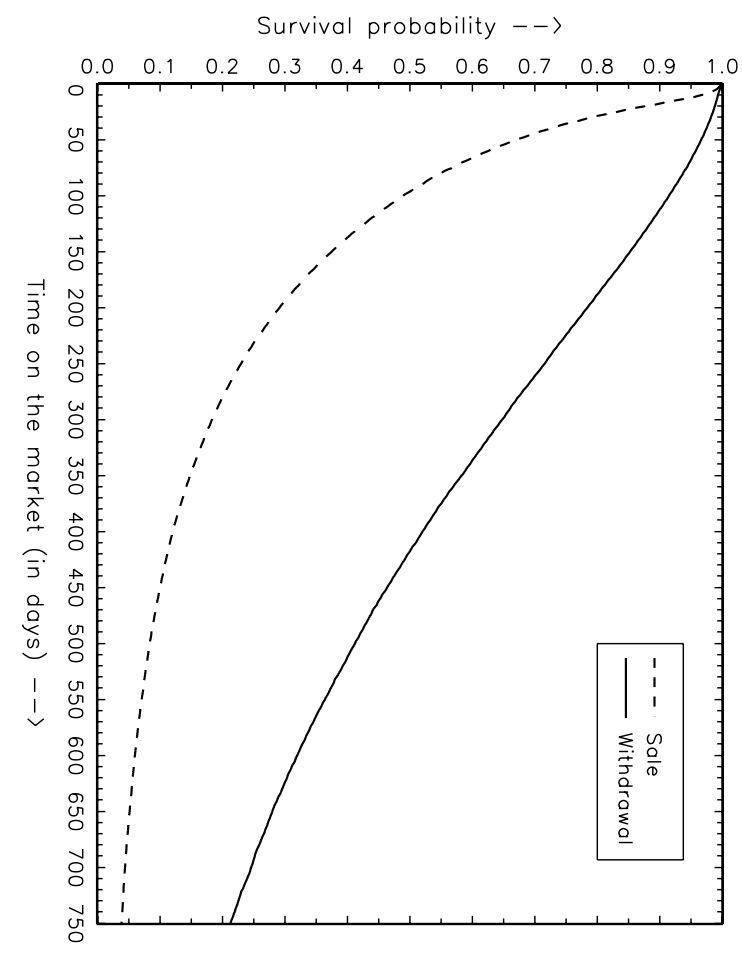

Figure 1: Kaplan-Meier estimates for the survivor function to selling the house and withdrawal.

average reduction is $5.5 \%$.

\section{$5 \quad$ Estimation Results}

\subsection{Parameter Estimates}

In this section we discuss the results of our empirical analyses. First, we present the parameter estimates of our baseline model and provide some model simulations, while in the next subsection we perform sensitivity analyses.

For the piecewise constant duration dependence we choose the following intervals: 0-30 days, 31-60 days, 61-120 days, 121-180 days, 181-270 days, 271-360 days, 361-720 days, and beyond 720 days. However, in the hazard to withdrawing we merge the last two intervals to one interval beyond 361 days, 


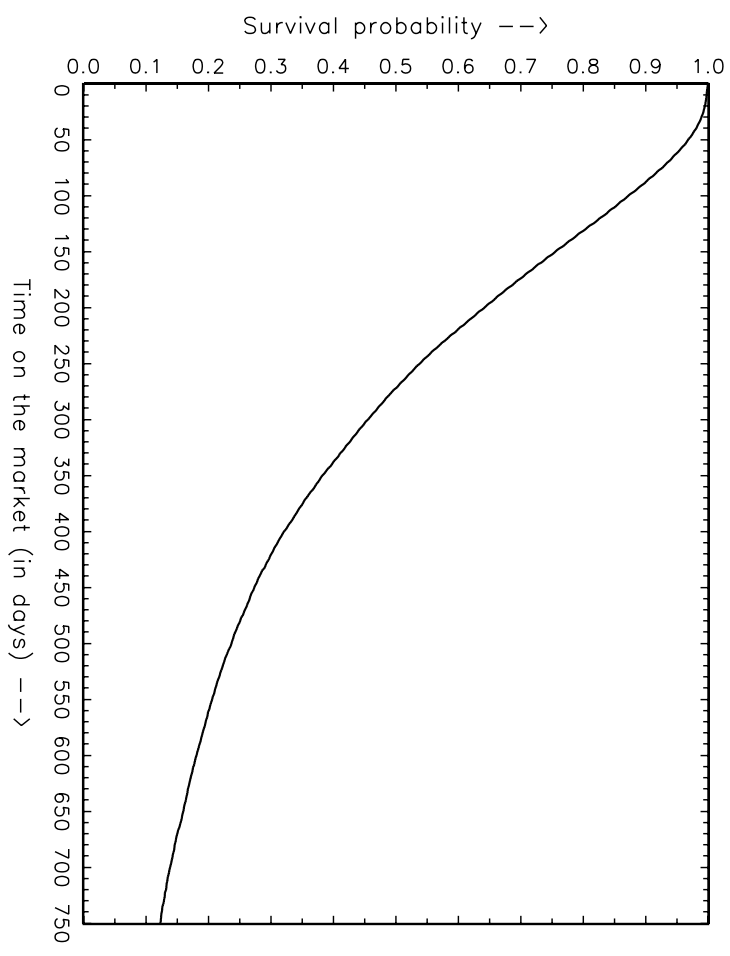

Figure 2: Kaplan-Meier estimates for the survivor function for reducing the list price.

and in the repricing hazard we merge all intervals beyond 181 days. For the unobserved heterogeneity we have three mass points $(K=3)$. We allowed for additional mass points, but the probability mass associated to a fourth point converged towards 0 , and the loglikelihood function did not show any improvement. The vector of observed characteristics includes 61 variables.

Table 2 presents the parameter estimates of our baseline model. The main parameters of interest are $\delta_{s}$ and $\delta_{w}$, which represent the effect of a list-price reduction on, respectively, the rate at which a house is sold and withdrawn from the market. The parameter estimates show that a list-price reduction has both a positive and significant effect on selling the house and withdrawing the house from the market. The estimated value of $\delta_{s}$ is 0.606 , which implies that after a list-price reduction the rate at which the house is sold increases with $(\exp (0.606)-1) \times 100 \%=83 \%$. A list-price reduction increases the rate at which the house is withdrawn from the market with 
$(\exp (0.366)-1) \times 100 \%=44 \%$. Recall that in a housing market with symmetric information, there is no important role for list prices. Our results indicate that list-price reductions have very substantial effects. This should thus be interpreted as evidence in favor of asymmetric information between sellers and buyers in the housing market.

The distribution of unobserved heterogeneity shows three mass points. Most probability mass (83\%) is located at houses which are sold relatively fast and have a very low rate of withdrawal. This might be regular houses where the seller is determined to sell the house, for example, because the seller already obtained another house. These houses have an average rate of repricing. The second mass point ( $10 \%$ probability) describes houses which both have a high rate of sale and of withdrawal, and also a high rate of repricing. The final $7 \%$ probability is located at the third mass point, which describes houses with a low rate of sale and also with a low rate of repricing, but with a high rate of withdrawal. These might be relatively patient sellers or seller preferring to sell their house first (for a sufficiently high price) before buying a new house. The main conclusion is that there are relevant unobserved characteristics which causes dependency between the three hazards.

There is significant and substantial negative duration dependence in the rate of selling, so it becomes less likely to sell the house the longer it is on the market. This might indicate that houses get stigmatized once they are for sale for a longer period. Stigmatization would imply the presence of a characteristic unobserved by buyers which might, for example, be revealed during inspections (e.g. Taylor, 1999). This might suggest asymmetric information, but it is not necessary that the seller has more information. An alternative explanation could be that a house which is new on the market is considered by the current stock of all potential buyers. Once they have decided against buying the house, the house can only be sold to new buyers entering the housing market. This argument is similar to stock-flow matching models for the labor market (e.g. Coles and Smith, 1998). The duration dependence in the rate of withdrawing a house from the market is positive and significant. So the longer the house is on the market the more likely it becomes that the seller withdraws the house. Also there is positive and significant duration dependence in the rate or repricing. Our paper is the 
Table 2: Estimation results of the baseline model.

\begin{tabular}{|c|c|c|c|c|c|c|}
\hline & \multicolumn{2}{|c|}{ Sale Hazard $\theta_{s}$} & \multicolumn{2}{|c|}{ Exit Hazard $\theta_{w}$} & \multicolumn{2}{|c|}{ Repricing Hazard $\theta_{p}$} \\
\hline Effect of repricing $\delta$ & 0.606 & $(0.026)$ & 0.366 & $(0.075)$ & & \\
\hline \multicolumn{7}{|c|}{ Unobserved heterogeneity } \\
\hline$v_{1}$ & -2.739 & $(0.970)$ & -13.901 & $(1012.179)$ & -12.577 & $(1.898)$ \\
\hline$v_{2}$ & -2.789 & $(0.756)$ & -7.720 & $(1.650)$ & -12.146 & $(1.403)$ \\
\hline$v_{3}$ & -4.120 & $(0.764)$ & -7.847 & $(1.639)$ & -13.675 & $(1.406)$ \\
\hline$p_{1}$ & 0.834 & $(0.355)$ & & & & \\
\hline$p_{2}$ & 0.103 & $(0.017)$ & & & & \\
\hline$p_{3}$ & 0.062 & $(0.754)$ & & & & \\
\hline \multicolumn{7}{|l|}{ Duration dependence } \\
\hline$\lambda_{0}(0-30$ days $)$ & 0 & & 0 & & 0 & \\
\hline$\lambda_{1}(31-60$ days $)$ & 0.033 & $(0.016)$ & 0.069 & $(0.062)$ & 1.167 & $(0.053)$ \\
\hline$\lambda_{2}(61-120$ days $)$ & -0.268 & $(0.017)$ & 0.322 & $(0.058)$ & 1.874 & $(0.049)$ \\
\hline$\lambda_{3}(121-180$ days $)$ & -0.441 & $(0.022)$ & 0.595 & $(0.067)$ & 2.193 & $(0.053)$ \\
\hline$\lambda_{4}(181-270$ days $)$ & -0.502 & $(0.027)$ & 0.698 & $(0.078)$ & 2.383 & $(0.061)$ \\
\hline$\lambda_{5}(271-360$ days $)$ & -0.498 & $(0.037)$ & 0.833 & $(0.096)$ & $\ldots$ & \\
\hline$\lambda_{6}(361-720$ days $)$ & -0.448 & $(0.049)$ & 0.977 & $(0.122)$ & $\ldots$ & \\
\hline$\lambda_{7}(>720$ days $)$ & -0.524 & $(0.125)$ & $\ldots$ & & $\ldots$ & \\
\hline \multicolumn{7}{|c|}{ Calendar time effects } \\
\hline 2005-Q1 & 0 & & 0 & & 0 & \\
\hline 2005-Q2 & 0.055 & $(0.039)$ & 0.109 & $(0.135)$ & 0.226 & $(0.107)$ \\
\hline 2005-Q3 & 0.144 & $(0.039)$ & -0.185 & $(0.134)$ & 0.035 & $(0.105)$ \\
\hline 2005-Q4 & 0.211 & $(0.038)$ & -0.035 & $(0.131)$ & 0.094 & $(0.105)$ \\
\hline 2006-Q1 & 0.239 & $(0.039)$ & 0.142 & $(0.129)$ & 0.107 & $(0.105)$ \\
\hline 2006-Q2 & 0.196 & $(0.038)$ & 0.038 & $(0.130)$ & 0.249 & $(0.104)$ \\
\hline 2006-Q3 & 0.155 & $(0.039)$ & -0.064 & $(0.130)$ & 0.034 & $(0.105)$ \\
\hline 2006-Q4 & 0.140 & $(0.039)$ & 0.034 & $(0.129)$ & 0.093 & $(0.104)$ \\
\hline 2007-Q1 & 0.209 & $(0.039)$ & 0.133 & $(0.128)$ & 0.171 & $(0.104)$ \\
\hline 2007-Q2 & 0.177 & $(0.038)$ & 0.087 & $(0.128)$ & 0.301 & $(0.104)$ \\
\hline 2007-Q3 & 0.083 & $(0.039)$ & 0.110 & $(0.128)$ & 0.038 & $(0.105)$ \\
\hline 2007-Q4 & 0.067 & $(0.039)$ & 0.107 & $(0.128)$ & 0.143 & $(0.104)$ \\
\hline List price premium & -0.632 & $(0.031)$ & 0.106 & $(0.076)$ & 0.228 & $(0.057)$ \\
\hline Additional controls & \multicolumn{2}{|c|}{ Yes } & \multicolumn{2}{|c|}{ Yes } & \multicolumn{2}{|c|}{ Yes } \\
\hline Log likelihood & \multicolumn{6}{|c|}{$-3,401,344.37$} \\
\hline Observations & \multicolumn{6}{|c|}{498,369} \\
\hline
\end{tabular}

Note.-List-price premium is the difference between the log of the initial list price of the house and the predicted log value of the initial list price of the house. The predicted $\log$ value of the list price is based on a log-linear hedonic regression. Additional controls are for number of rooms, $\log$ (lotsize), $\log$ (lotsize) squared, $\log$ (floorsize), $\log$ (floorsize) squared, construction period, type of house (or type of apartment), presence of a lift in the apartment building, parking facility, garden location, isolation, location to busy roads, groundlease, inside and outside quality of the house, and regions. Standard errors are in parentheses. 
first showing empirical evidence in favor of positive duration dependence in repricing. This is consistent with the theory in Lazear (1986), showing that prices decline in time on the market.

To capture the effects of business cycles, we included a flexible time trend containing indicators for each quarter. The parameter estimates show an increasing trend in the rate of selling a house during 2005 and a decreasing trend starting in the second quarter of 2007. There are no significant calendar-time effects in the rate of withdrawing a house. In the rate of repricing a house, there are only significant increases in each second quarter of the year. This is usually the quarter of the year, which real estate brokers consider as the best moment of selling a house. It might be that, therefore, real estate brokers advise sellers to reduces their list price in this quarter.

In the estimation we also included the list-price premium as explanatory variable. Recall that the list-price premium is defined as the list price of the house compare to an hedonic list price for the house. A positive list-price premium thus implies that the house is priced higher than comparable houses in the market. It should be stressed that no strong causal interpretation should be given to the covariate effects of the list-price premium. However, the estimation results are consistent with most theoretical predictions (e.g. Lazear, 1986). Houses with a higher list-price premium are less likely to be sold, are more likely to be withdrawn from the market, and more likely to be repriced. These results (and also all other parameter estimates) are robust against alternative specification of the list-price premium, for example, the list price relative to the hedonic selling price.

A list-price reduction has a positive and significant effect on both the rate at which are sold and withdrawn from the market. The changes in these rates are quite substantial. In Table 3 we present how these effects translate in the probability of selling and withdrawing a house from the market. In particular, we consider list-price changes after a house has been on the market for one month (30 days), one quarter (91 days) or half a year (182 days), and we focus on selling or withdrawing the house within one quarter, half a year and one year (365 days). In the model calculations we only take into account houses entering the market in 2005 and 2006. ${ }^{4}$ Column (1) shows that if list

\footnotetext{
${ }^{4}$ In the model calculations we follow houses for at most one year. Since we modeled
} 
Table 3: Predicted probabilities for the baseline model.

\begin{tabular}{lrrrr}
\hline \hline & \multicolumn{4}{c}{ Moment of repricing } \\
& never & 30 days & 91 days & 182 days \\
\hline In market at repricing & & $79.4 \%$ & $52.8 \%$ & $33.5 \%$ \\
& & & & \\
Sold within 91 days & $44.0 \%$ & $56.7 \%$ & $44.0 \%$ & $44.0 \%$ \\
Withdrawn within 91 days & $3.2 \%$ & $4.2 \%$ & $3.2 \%$ & $3.2 \%$ \\
& & & & \\
Sold within 182 days & $60.7 \%$ & $73.9 \%$ & $68.6 \%$ & $60.7 \%$ \\
Withdrawn within 182 days & $5.9 \%$ & $7.2 \%$ & $7.1 \%$ & $5.9 \%$ \\
& & & & \\
Sold within 365 days & $74.8 \%$ & $83.5 \%$ & $81.6 \%$ & $79.5 \%$ \\
Withdrawn within 365 days & $9.7 \%$ & $10.3 \%$ & $11.0 \%$ & $11.0 \%$ \\
\hline \hline
\end{tabular}

Note.-Only houses entering the market in 2005 and 2006 are taken into account.

prices would never be reduced about $44 \%$ of all houses are sold within one quarter (and 3.2\% of the houses are withdraw from the market). A list-price reduction after one month increase the percentage of houses sold within one quarter to almost $57 \%$ (see Column (2)). This is substantial, particularly since after 30 days only about $79 \%$ of the houses are still on the market. A list-price reduction also increases withdrawing the house from the market. However, a late list-price reduction 182 days compared to 30 days has a more substantial effect on withdrawing the house than selling the house within 365 days (see Column (2) and (4)). In the next subsection we focus more on the importance of the timing of a list-price reduction.

\subsection{Sensitivity Analyses}

In this subsection we examine the robustness of our parameter estimates with respect to the model specification. We provide a number of sensitivity analyses, and mainly focus on the effects of list-price reductions.

In the first sensitivity analysis we consider the importance of allowing for dependency between the different hazard rates. Independent hazards implies that the unobserved heterogeneity components in the three hazard rates are

business-cycle effects using quarterly dummies, we cannot say anything beyond January 1 , 2008 without imposing some arbitrary extrapolation. Therefore, in the model calculations we ignore houses entering the market in 2007. 
independent of each other. Note that this does not mean that unobserved heterogeneity is absent from the model. From the first plane in Table 4 it can be seen that not correcting for dependency between the hazards causes an increase in the estimated effects of the list-price reductions. Compared to the baseline model the effect of a list-price reduction on selling the house increases from 0.606 to 0.771 , and given the small standard errors these effects are statistically different from each other. The effect on withdrawing increases from 0.370 in the baseline model to 0.405 . These results show the importance of self selection in the decision to reduce the list price. Obviously houses with a lower rate of selling are more likely to be repriced, which confirms the argument of Caplin and Leahy (1996) that self selection matters in markets with frictions.

Next, we consider the size of the list-price reduction. Therefore, we interact the effect of the list-price reductions with the magnitude of the list-price reduction, measured as fraction decrease in the list price. The specification of the effect of a list-price reduction is thus $\delta_{0}+\delta_{1} \Delta P$, where $\Delta P$ is the size of the list-price reduction. The second plane in Table 4 shows that the size of the list-price reduction has a positive and significant effect on selling the house. If the list price is more substantial the effect of the list-price reduction is larger. Recall from Section 4 that the average list-price reduction in the data is $5.5 \%$. So for the average list-price reduction the effect on the hazard of sale is 0.630 , which is not very different from the homogeneous effect estimated in our baseline model. The size of the list-price reduction does not have a significant effect on the rate of withdrawing the house from the market. It is important to stress that although these results provide some indication about the effects, it is difficult to draw strong causal conclusions. This is the case because the size of the list-price reduction is most likely endogenous which is not taken into account in our model.

Next, we want to know if the timing of the list-price reduction is important. So does a list-price reduction if the house is only shortly on the market have a different effect than a list-price reduction if the house is already for sale for a longer period. Therefore, we alow the effect depends on time on the market. In particular, we allow the effect to be different within three time intervals, $(i)$ within the first 60 days, $(i i)$ between 60 days and 182 days, and 
Table 4: Sensitivity analyses on the effect of list-price reductions.

\begin{tabular}{|c|c|c|c|c|c|c|}
\hline & \multicolumn{2}{|c|}{ Sale Hazard $\theta_{s}$} & \multicolumn{2}{|c|}{ Exit Hazard $\theta_{w}$} & \multicolumn{2}{|c|}{ Transaction price } \\
\hline Effect of repricing: $\delta$ & 0.771 & $(0.016)$ & 0.405 & $(0.036)$ & & \\
\hline $\begin{array}{l}\text { Repricing interacted with magnitude } \\
\text { Effect of repricing: } \delta_{0} \\
\text { Interaction with magnitude } \delta_{1}\end{array}$ & $\begin{array}{l}0.506 \\
2.270\end{array}$ & $\begin{array}{l}(0.025) \\
(0.290)\end{array}$ & $\begin{array}{r}0.370 \\
-0.164\end{array}$ & $\begin{array}{l}(0.060) \\
(0.600)\end{array}$ & & \\
\hline $\begin{array}{l}\text { Moment of repricing } \\
\text { Repricing within } 60 \text { days } \delta_{1} \\
\text { Repricing between } 60 \text { and } 182 \text { days } \delta_{2} \\
\text { Repricing after } 182 \text { days } \delta_{3}\end{array}$ & $\begin{array}{l}0.464 \\
0.649 \\
0.762\end{array}$ & $\begin{array}{l}(0.032) \\
(0.026) \\
(0.034)\end{array}$ & $\begin{array}{l}0.650 \\
0.330 \\
0.150\end{array}$ & $\begin{array}{l}(0.076) \\
(0.060) \\
(0.072)\end{array}$ & & \\
\hline $\begin{array}{l}\text { Model with transaction price } \\
\text { Effect of repricing } \delta_{1} \\
\text { Days on the market } \delta_{2}\end{array}$ & 0.603 & $(0.020)$ & 0.400 & $(0.046)$ & $\begin{array}{l}0.308 \\
0.00216\end{array}$ & $\begin{array}{l}(0.020) \\
(0.00008)\end{array}$ \\
\hline
\end{tabular}

Note.-Similar specification and controls as in the baseline model. Full sets of parameter estimates are available on request. Standard errors are in parentheses. 
(iii) after 182 days on the market. The third plane in Table 4 shows that the effect of a list-price reduction on the hazard of selling the house increases in time on the market, while the opposite is the case in the hazard of withdrawing. However, recall that we found negative duration dependence in the selling hazard and positive duration in the rate of withdrawing the house from the market. So in absolute terms the change in selling and withdrawing probabilities due to list-price reductions do not vary that much in the timing of the list-price reduction.

A list-price reduction reduces the average duration until selling a house. In a housing market with asymmetric information, time on the market may be a negative signal and thus negatively affect the selling price. Other than this indirect effect, list-price reductions may also have a direct effect on the transaction price simply because a list-price reduction provides a signal to the market. A first indication is that houses with an observed list price reduction are sold, on average, $3.6 \%$ below their hedonic value, while houses without a list price reduction are sold $0.9 \%$ above their hedonic value. However, we showed above that there are also unobserved characteristics affecting the decision to reduce the list price. To take this into account we extend our model with a model for transaction prices. We use also a hazard rate model for the transaction prices $p$, with the density function

$$
f_{t}\left(p \mid t_{p}, t, \tau_{0}, x, v_{t}\right)=\theta_{t}\left(p \mid t_{p}, t, \tau_{0}, x, v_{t}\right) \exp \left(-\int_{0}^{p} \theta_{t}\left(s \mid t_{p}, t, \tau_{0}, x, v_{t}\right) d s\right)
$$

with

$$
\theta_{t}\left(p \mid t_{p}, t, x, v_{t}\right)=\lambda_{t}(p) \psi_{t}\left(\tau_{0}+t\right) \exp \left(x^{\prime} \beta_{t}+\delta_{t, 1} \cdot I\left(t_{p}<t\right)+\delta_{t, 2} \cdot t+v_{t}\right)
$$

So $\psi_{t}\left(\tau_{0}+t\right)$ denotes calendar-time effects at the moment of selling the house, $I\left(t_{p}<t\right)$ describes if the list price was reduced while the house was on the market, and $t$ is the time the house was on the market before being sold. The unobserved heterogeneity term $v_{t}$ can be correlated to the unobserved heterogeneity terms in the selling, withdrawing and repricing hazard to account for endogeneity. The parameters of interest are the direct effect of a listprice reduction $\delta_{t_{1}}$, and $\delta_{t, 2}$ capturing the effect of time on the market on the 
transaction price. Using a hazard rate model for transaction prices follows Donald, Green and Paarsch (2000) who present hazard rate specifications as very flexible models for wages.

The bottom plane of Table 4 shows the estimation results for the main parameters of interest. First, it should be noted that jointly modeling the transaction price hardly changes the parameter estimates obtained from the baseline model. The parameter estimate of a list-price reduction on the hazard for the transaction price is positive, which implies that a list-price reduction reduced the expected transaction price. There is thus a substantial disadvantage to the seller of reducing the list price. However, also the coefficient of the time on the market is positive, implying that the expected transaction price reduces in the time the house was on the market before the selling it. However, only if the list-price reduction reduces the time on the market with more that $\frac{0.308}{0.00216} \approx 143$ days, the indirect effect dominates the direct effect on the transaction price.

Finally, Haurin (1988) distinguishes between regular houses and atypical houses. We also considered this distinction. First, we included a dummy variable for atypical houses (using the Haurin, 1988; measure) in our model. This did not change any of the estimation results. In particular, the effects of the list-price reductions were unaffected. Second, we estimated the model again without atypical houses, which excluded $10 \%$ of the data. The effect of the repricing slightly changed to 0.598 (s.e. 0.028) on the hazard of sale and 0.364 (s.e. 0.078 ) on the hazard of withdrawal. This indicates that our results are not driven by atypical houses changing list prices, but also hold in the market for regular houses.

\section{Conclusions}

The main focus of this paper is on the effect of lowering list prices on the time at which a house is on the market. In our empirical model we explicitly allow for selectivity in list-price reductions. We also take into account that houses can also be taken off the market without being sold and that such exits might not be exogenous. Our model is a timing-of-events model described in Abbring and Van den Berg (2003). 
Our empirical results show that list-price reductions significantly increase the hazard of sale, but also increase the hazard at which the house is taken off the market. The effects are very substantial. A list-price reduction raises the selling rate by $83 \%$, and the rate of withdrawing by $44 \%$. Since list prices do not have any formal legal role in the Dutch housing market, list prices can only be used by the seller to provide signals to the market. In a market with symmetric information, signals do not add any information. Therefore, we interpret the substantial and significant effect of the list-price reductions as evidence in favor of the presence of asymmetric information in the housing market.

In the sensitivity analyses, we have also shown that the timing and the magnitude of the list-price reduction matter. Furthermore, we have stressed the importance of allowing for selectivity in list-price reductions and taking withdrawals from the market into account. Our results confirm the argument made by Caplin and Leahy (1996) that self selection-effects matter in markets with frictions. Finally, we have investigated the effect of list-price reductions on the transaction price. List-price reductions reduce the expected transaction price, which is the direct effect. However, also the time on the market before selling the house has a negative effect on the transaction price. The indirect effect of a list-price reduction is thus that it reduced the time on the market which again increases the expected transaction price.

We have found negative duration dependence in the hazard of sale, which might also be the consequence of houses getting stigmatized due to the presence of asymmetric information. The parameter estimates show positive duration dependence in the rate of withdrawal and the repricing hazard. This paper is actually the first finding empirical evidence in favor of positive duration dependence in the hazard of repricing, which is consistent with Lazear (1986). Also the finding that higher list prices increase the likelihood of listprice reductions is consistent with Lazear (1986), although our estimate for the latter is merely an association than an causal effect. 


\section{References}

Abbring, J.H. and G.J. van den Berg (2003), The Nonparametric Identification of Treatment Effects in Duration Models, Econometrica 71(5), $1491-1517$.

Albrecht, J., P. Gautier and S. Vroman (2010), Directed Search in the Housing Market, Tinbergen Institute, Working Paper.

Ball, M. (2009), RICS European Housing Review 2009, RICS, London.

Caplin, A., and J. Leahy (1996), Trading Costs, Price, and Volume in Asset Markets, The American Economic Review 86(2), 192-196.

Coles, M.G. and E. Smith (1998), Marketplaces and Matching, International Economic Review 39(1), 239-254.

De Wit, E.R. (2009), Competing Risks in a Time-on-the-Market Analysis, Working Paper.

Donald, S.G., D.A. Green and H.J. Paarsch (2000), Differences in Wage Distributions between Canada and the United States: An Application of a Flexible Estimator of Distribution Functions in the Presence of Covariates, The Review of Economic Studies 67(4), 609-633

Harding, J.P., S.S. Rosenthal and C.F. Sirmans (2003), Estimating Bargaining Power in the Market for Existing Homes, The Review of Economics and Statistics 85(1), 178-188.

Haurin, D. (1988), The Duration of Marketing Time of Residential Housing, Journal of the American Real Estate and Urban Economics Association 16(4), 396-410.

Haurin, D.R., J.L. Haurin, T. Nadauld and A. Sanders (2006), List Prices, Sale Prices, and Marketing Time: An Application to U.S. Housing Markets, Working Paper.

Heckman, J.J. and B.E. Honoré (1989), The Identifiability of the Competing Risks Model, Biometrica 76(2), 325-330.

Heckman, J. and B. Singer (1984), A Method for Minimizing the Impact of Distributional Assumptions in Econometric Models for Duration Data, Econometrica 52(2), 271-320. 
Horowitz, J.L. (1992), The Role of the List Price in Housing Markets: Theory and an Econometric Model, Journal of Applied Econometrics 7(2), 115129 .

Huang, J. and R.B. Palmquist (2001), Environmental Conditions, Reservation Prices, and Time on the Market for Housing, Journal of Real Estate Finance and Economics 22(2), 203-219.

Knight, J.R. (2002), Listing Price, Time on Market, and Ultimate Selling Price: Causes and Effects of Listing Price Changes, Real Estate Economics 30(2), 213-237.

Lazear, E.P. (1986), Retail Pricing and Clearance Sales, The American Economic Review 76(1), 14-32.

Merlo, A. and F. Ortalo-Magné (2004), Bargaining over residential real estate: evidence from England, Journal of Urban Economics 56(2), 192-216.

Olsen, E.O. (1969), A Competitive Theory of the Housing Market, The American Economic Review 59(4), 612-622.

Pryce, G. and K. Gibb (2006), Submarket Dynamics of Time to Sale, Real Estate Economics 34(3), 377-415.

Rosen, S. (1974), Hedonic Prices and Implicit Markets: Product Differentiation in Pure Competition, The Journal of Political Economy 82(1), 34-55.

Taylor, C.R. (1999), Time-on-the-Market as a Sign of Quality, The Review of Economic Studies 66(3), 555-578.

Wheaton, W.C. (1990), Vacancy, Search, and Prices in a Housing Market Matching Model, The Journal of Political Economy 98(6), 1270-1292.

Zuehlke, T.W. (1987), Duration Dependence in the Housing Market, The Review of Economics and Statistics 69(4), 701-709. 